\title{
Happiness and childbearing across Europe
}

\author{
Arnstein Aassve* \\ arnstein.aassve@unibocconi.it
}

Alice Goisis*

alice.goisis@unibocconi.it

Maria Sironi*

maria.sironi@unibocconi.it
${ }^{*}$ Carlo F. Dondena Centre for Research on Social Dynamics Università Bocconi
via Guglielmo Röntgen 1
20136 Milan
Italy

\begin{abstract}
In this paper we analyse the relationship between happiness and childbearing taking a comparative perspective. We argue that fertility and happiness are somewhat linked and we investigate whether there are important differences across European countries. Using happiness as a well-being measure offers important benefits over income especially when interest lies in understanding how individuals' wellbeing is associated with childbearing outcomes. We use the European Social Survey (ESS) and apply simple regression techniques, controlling for country differences, and find indeed a positive and significant association between happiness and childbearing. However, this association depends, especially for mothers, on location, partnership status, income levels and job status.
\end{abstract}

\section{Keywords}

Happiness, childbearing, European social survey 


\section{Introduction}

When looking across European countries we find differences in wellbeing levels, desired fertility levels, social norms, and institutional constraints, as well differences in the way welfare provision is organised. If we take an economic view point, assuming that couples aim to maximise their levels of utility or wellbeing, presumably couples choose to have children because it increases their wellbeing. Is it then possible that differences in fertility are driven, at least partly, by differences in the wellbeing couples derive from childbearing? This would certainly be the case if European couples during their childbearing age faced differences in the resources available to them. For instance, we know that European countries differ tremendously in the way the state provides support to couples with young children. Rather than exploring how these factors impact childbearing, we take a more indirect approach by asking whether childbearing is associated with individuals' wellbeing - here measured by individuals' own subjective assessment of their happiness and life satisfaction. In particular, interest lies in whether there are differences across countries in the association between subjective measures of well-being and childbearing. Is it possible that average levels of parental well-being are lower in countries where fertility is more limited? Moreover, would such an analysis reveal patterns consistent with how governments organise their support to couples with young children?

By taking a comparative perspective and using data from the European Social Survey (ESS from now onwards) we aim to shed some insights into these questions. The ESS is ideal for comparative analysis and includes specific questions where individuals are asked to grade their level of happiness and life satisfaction on a scale from 0 to 10, the latter indicating the highest level. The ESS also contains information 
about childbearing. Consequently, we are able to consider not only how childbearing is related to individuals' happiness, but also how this relationship differs across European countries.

The paper is organized as follows: section 2 deals with the background, section 3 deals with the European Social Survey; in section 4 we present the descriptive analysis of the sample; section 5 contains the outcomes obtained from the regressions where we investigate the relationship between childbearing and subjective well-being, progressively adding controls for country differences and individual characteristics. Section 6 concludes.

\section{Background}

Do children increase couples' well-being levels? To what extent do parents differ in the wellbeing they derive from having children? There are of course many reasons why couples end up wanting to have children. If we take the economics perspective, there are two key arguments why couples choose to have children. One strand considers children as an investment good (Neher, 1971; Leibenstein, 1975; Caldwell, 1978; Boldrin and Jones, 2002). In developing countries, children may serve as cheap labour (Moav, 2005) in the family business or on the farm. They also serve as an insurance and social protection in old age. Another strand considers children as a consumption good (Barro and Backer, 1988). More precisely, couples simply go on to have children because they increase their utility. Thus, it is assumed that couples have an altruistic utility function that incorporates also the utility of the future generation and thus, by increasing the well-being of children, parents increase their own utility. In other words, children are assumed to be a "normal" good which implies parents' utility increases from any increase in the utility of their children. In developed 
countries with well functioning welfare provision and little need for using children as cheap labour, these arguments make sense. An implication of the argument is that parents do not necessarily demand many children, instead they have fewer children but make greater investment in each of them (Becker, 1991).

But looking at birth rates across European countries in the last few decades, and assuming there is some hold in these economic arguments, one might get the impression that wellbeing or utility associated with having children has declined somewhat. We find reductions in fertility levels particularly severe in Mediterranean countries and in the former socialist countries in Central and Eastern Europe. This is in contrast to the Scandinavian countries, and the Liberal countries of the UK and the US, but also France - where fertility levels have remained high. The factors behind these diverse fertility rates are obviously complex. For the former socialist countries of Central and Eastern Europe, fertility declined sharply after the fall of the Iron Curtain. Prospective couples in these countries faced sudden societal change accompanied with economic decline and increased unemployment (Aassve et al, 2006). In other words, individuals faced a new challenging environment full of uncertainty. These dramatic changes are important in explaining the decline in fertility rate in these countries. The fertility decline in Mediterranean countries is somewhat more difficult to explain. One of the possible explanations is that, during the last decades, European societies have undergone major social and cultural changes, which have hugely affected the perception of traditional values concerning family and reproduction. For instance, European societies have experienced a postponement of different demographic events: young women and men are devoting more time to education, leave parental home and get married later. As a consequence, they also form families later with respect to the past and perhaps smaller ones. Women have 
reached economic independence as the result of higher educational levels. On the other hand, men tend increasingly more to avoid stable partnership and parenthood as they appear more careers oriented. Individual lives have become more flexible but also more uncertain and these facts have important consequences on the timing and importance attributed to certain demographic events. The other conventional idea is that state welfare provision is weak, especially for couples with young children. Family relatives, especially grand parents, are expected - more than in most other countries - not only to give support in terms of helping out on childcare, but also to provide more general economic support. Often this is materialised in young individuals and couples living in the parental household. Whether such an organisation of welfare is compatible with new and emerging attitudes and value orientations, largely emerging from expansion of educational systems, is debatable. The social Democratic welfare system of the Scandinavian countries serves as a stark contrast. Here support to couples with young children is particularly generous, and it is often claimed to be an important reason behind high rates of childbearing.

When comparing different European countries, it becomes clear that there are important differences in the way individuals and couples face different constraints in their childbearing decisions, and their levels of wellbeing may differ as a result. A key difficulty is of course how to appropriately measure individuals' wellbeing. Whereas sophisticated approaches have been developed within psychology, the predominant perspective in economics is to measure wellbeing or utility in terms of some money metric measure. The usual approach for developed countries is to use net household income, which is equivalised by a suitable scale, capturing the composition of the household and economies of scale in household consumption. The approach taken 
for developing countries follows the same principle, though here wellbeing (or lack thereof) is measured in terms of household consumption expenditure. Independent of whether wellbeing is defined over household income or consumption expenditure, the use of equivalence scales introduces a serious problem, especially when the focus is on children of the household. The problem lies in the fact that adding a child to the household decreases the per capita wellbeing all else equal. From a revealed preference perspective this is a perverse outcome: a couple choosing to have a child, presumably because it increases their utility or subjective wellbeing, will be recorded with a reduced economic wellbeing. The use of happiness as a measure of wellbeing or utility has become popular, and there is now a vast range of papers analysing happiness. A key argument is that individuals' true wellbeing or utility are better captured by their subjective assessment of their wellbeing, i.e. happiness and life satisfaction. Whereas income and consumption expenditure are the traditional ways of measuring wellbeing, an intriguing finding of the literature is that the correlation between happiness and income is not always very strong (Easterlin, 2001). Traditionally economic research has focused on collecting and analyzing economic data, while little attention has been paid to measuring attitudes and emotional states. This is why the Nobel laureate Kahneman, in order to allow economists to say something about people's social experiences and their quality of life, has called for the establishment of national well-being accounts (Aslam, Corrado 2007). One popular hypothesis is that well-being is primarily determined by personality traits and other genetic factors and highly stable over the life course (Easterlin, 2003; Easterlin 2005; Behrman, Kohler, Skytthe, 2005). This view is known as the set point theory and predicts that a substantial part of variation in well-being is due to social or biological endowments that are unobserved in social surveys, which thus explains 
why happiness does not necessarily follow closely observed income levels (Oswald, 1997). Happiness, used as a measure of wellbeing over income levels, offers important benefits.

Whereas measures of well-being provide many benefits over the use of income, several potential disadvantages have been raised. As brought up by Clark et al (2006), does a question asking about current happiness on some ordinal scale really provide a good assessment of current circumstances that relates to, for example, family life, job and income? Is it possible that or will the response also pick up transient factors such as having a cold or toothache, the weather, or their sports team's recent results? Moreover, can we compare responses of different people and carry out interpersonal or intertemporal comparison in happiness scores? Measurement issues such as the reliability and validity of the replies, whether respondents report their true feelings, and possible biases resulting from the context in which the question is asked, have been extensively studied (Diener, 1984 and Veenhoven, 1993). The general conclusion of this literature is that subjective indicators, though not perfect, do reflect respondents substantive feelings of wellbeing - in the words of psychologist Ed Diener (1984, p.551), these "measures seem to contain substantial amounts of valid variance" (Easterlin, 2001).

Although there is now a substantial literature on the comparative aspects of happiness (see surveys by Easterlin, 1994 and Veenhoven, 2000), very few have considered the links between childbearing and wellbeing. The work by Behrman, Kohler and Skytthe (2005) represents, however, an exception. Using Danish Twin Registry data, collected in 2002, they consider the effect of childbearing and partnership on happiness. A key issue concerns genetic endowments and predispositions affecting both the level of happiness (i.e. the outcome variable) and 
childbearing and marriage (the explanatory variables), thus giving rise to an omitted variable bias. In other words, genetically happier personality traits may be positively associated with both higher likelihood of partnership formation and childbearing. Behrman et al (2005) overcomes this problem by using data on monozygotic twins, which in essence allows them to control for otherwise unobserved traits such as preferences and capabilities driven by genetic dispositions, family background, and the neighbourhood in which the twins grew up. The estimates therefore represent the causal contributions of marriage and fertility towards individuals' happiness. Their analysis suggests a large positive effect of the first born child on mothers' happiness and significant positive impact of the first born boy on fathers' happiness. Interestingly, additional children beyond the first born do not give higher levels parental happiness. The econometric analysis shows that OLS regression tends to underestimate the happiness gains from the first child for women, while it overestimate the increases in men's subjective well being resulting from the first child. The results yield very interesting insights, namely that certain dimensions of partnership formation and childbearing have appreciable and persistent effects on happiness, which in essence rejects the set point theory and the almost complete dominance of endowments in affecting happiness (Behrman, Kohler, Skytthe, 2005). Two other recent papers deal with these topics, but they consider childbearing within the main framework of well-being and marriage or partnership, which is the main topic of their research question. The paper by Zimmermann and Easterlin (2006) find no significant effect of children on life satisfaction for both those individuals who remained married and those who did not. On the other side, the paper by Stutzer and Frey (2004), find a positive correlation between childbearing and having up to three 
children in the pooled estimation. In constrast, the fixed effect specification finds small but negative partial correlations for having one child or more.

Analysis of childbearing and happiness in a comparative perspective has been rather limited so far. Billari (2008) presents descriptive analysis from the Gender and Generations Surveys (GGS) of France, Germany, Bulgaria, Georgia, Russian and Hungary, showing a positive, albeit modest, positive effect of children on happiness. Interestingly, it appears that parental happiness is highest in the high fertility country of France.

Clearly the aim of our paper is different from that of Behrman et al. Given lack of longitudinal data and therefore repeated measures of well-being over time, we are not able to tell to what extent childbearing events may lead to changes in levels of happiness. That is, we are not able to say anything about causality, and clearly one might argue that there is reversed causality at play: happy and optimistic individuals may be more likely to marry and form families. The key contribution of our paper is the study happiness and childbearing adopting a comparative perspective.

\section{The European Social Survey (ESS)}

Information concerning couples' well-being and childbearing choices is taken from a cross-country comparative sample survey, the European Social Survey. The ESS is representative of the population aged 15 and over, resident within private households in each participating country. The ESS questionnaire contains a 'core' module, which is repeated in each survey round, and a series of 'rotating' modules, which vary in each bi-annual round. The minimum effective sample size for each country is 1,500 (or 800 for countries with less than 2 million inhabitants). The ESS has been developed to pursue a comparison between countries of the Eurasian region. So far 
three rounds have been conducted. 22 countries were included in Round 1 (2002), 26 in Round 2 (2004), and 25 in Round 3 (2006). The main aim of the ESS is that of outlining the attitudes of the different regions towards religion, politics, and moral issues, while also depicting their social habits and how they are changing over time. The first part of the survey pertains to individuals' value and ideological orientations. These orientations are partly the cause of people's opinions, behaviour and actions, thus becoming an important driver behind the social, political and economic changes within their respective societies. Secondly, the ESS considers individuals' cultural and national orientations, a feature being of key importance given the process of unification of the Western European countries. The third main area concerns the underlying social structure of society. Since values and social change are strongly driven by the social composition (e.g. education and occupations) identification of these factors is essential in drawing a correct picture of the social climate.

In our analysis we use a cumulative dataset which we constructed by pooling together data from countries that have fielded at least one of the three rounds; the cumulative file is based on the integrated file for each round. We use the cumulative dataset rather than single rounds since our analysis is not based on specifically designed items of the questionnaire available only in specific rounds. By combining multiple rounds we expand the sample size and we are able to include a higher number of countries which significantly contributes to the comparative perspective adopted throughout the paper. The cumulative dataset contains 25 countries. $^{1}$

\footnotetext{
${ }^{1}$ The complete cumulative dataset contains 30 countries, we had to exclude Estonia and Ukraine since data on income was missing for these two countries. We also exclude Israel, Turkey and Cyprus since our analysis mainly focuses on a European context.
} 


\section{Measuring happiness and childbearing}

In order to assess the individual level of happiness we use what has become more or less the standard in the literature. The variable is constructed from the question: "How happy are you?" on a scale ranging from 0 (extremely unhappy) to 10 (extremely happy). We restrict our attention to those individuals whose age ranges between 20 and 50, which makes the sample more homogenous, especially with regard to childbearing behaviour. Respondents younger than 20 are excluded from the sample as their level of happiness may be biased due to early pregnancy or particular financial difficulties. Parents older than 50 years of age are also excluded. Subjective levels of happiness change notably with age. Moreover, their response to happiness, and in particular with regard to childbearing, may be affected by their grand parent status.

After having reduced the size of the data set by taking out all the missing values for the variables of our interest and restricting the age class, we end up with a data set of 45518 observations.

Table 1 presents a set of descriptive statistic 
Table 1 Descriptive Table on Happiness and other relevant variables- by country

\begin{tabular}{|c|c|c|c|c|c|c|c|c|c|c|c|c|c|}
\hline \multirow{2}{*}{$\begin{array}{c}\text { Country } \\
\text { Code }\end{array}$} & \multirow{2}{*}{$\frac{\mathbf{N}^{\circ} \text { Obs }}{\#}$} & \multirow{2}{*}{$\begin{array}{c}\text { Gender } \\
\text { \% Male }\end{array}$} & \multicolumn{2}{|c|}{ Age } & \multicolumn{2}{|c|}{ Happiness } & \multicolumn{2}{|c|}{ Number of Children } & \multirow{2}{*}{$\begin{array}{c}\begin{array}{c}\text { At least } \\
1 \text { child }\end{array} \\
\%\end{array}$} & \multirow{2}{*}{$\begin{array}{c}\begin{array}{c}\text { Living with a } \\
\text { partner }\end{array} \\
\%\end{array}$} & \multirow{2}{*}{$\begin{array}{c}\text { Income } \\
\text { Mean }\end{array}$} & \multicolumn{2}{|c|}{$\begin{array}{c}\text { Years of } \\
\text { Completed } \\
\text { Education }\end{array}$} \\
\hline & & & Mean & St. Dev. & Mean & $\begin{array}{c}\text { St. } \\
\text { Dev. }\end{array}$ & Mean & St. Dev. & & & & Mean & St. Dev. \\
\hline AT & 2330 & 44.02 & 37.33 & 8.86 & 7.66 & 1.86 & 1.20 & 1.09 & 61.07 & 68.39 & 29916 & 13.03 & 3.01 \\
\hline $\mathrm{BE}$ & 2380 & 50.79 & 36.12 & 8.68 & 7.74 & 1.46 & 1.14 & 1.20 & 57.79 & 68.73 & 22781 & 13.30 & 3.50 \\
\hline BG & 445 & 38.49 & 37.68 & 8.88 & 5.53 & 2.50 & 1.22 & 0.97 & 73.25 & 74.15 & 3596 & 11.75 & 3.05 \\
\hline $\mathrm{CH}$ & 2573 & 47.42 & 37.34 & 7.66 & 8.10 & 1.38 & 1.17 & 1.15 & 57.71 & 73.90 & 58500 & 12.21 & 3.87 \\
\hline $\mathrm{CZ}$ & 1176 & 47.25 & 37.07 & 8.44 & 7.14 & 1.93 & 1.23 & 1.00 & 69.51 & 72.57 & 13096 & 12.87 & 2.43 \\
\hline $\mathrm{DE}$ & 3421 & 48.59 & 37.15 & 8.39 & 7.12 & 1.96 & 0.94 & 1.03 & 53.06 & 63.82 & 31300 & 14.02 & 3.10 \\
\hline DK & 2036 & 50.74 & 36.56 & 8.32 & 8.28 & 1.33 & 1.12 & 1.13 & 58.73 & 71.86 & 44051 & 14.54 & 3.56 \\
\hline ES & 1745 & 50.57 & 35.45 & 8.38 & 7.64 & 1.61 & 0.93 & 1.08 & 51.13 & 62.79 & 26744 & 13.35 & 4.81 \\
\hline FI & 2687 & 49.83 & 35.61 & 8.81 & 8.08 & 1.37 & 1.03 & 1.21 & 52.84 & 69.71 & 32288 & 14.33 & 3.27 \\
\hline FR & 1698 & 46.94 & 36.58 & 8.22 & 7.38 & 1.75 & 1.26 & 1.20 & 62.88 & 72.38 & 31812 & 13.61 & 3.45 \\
\hline GR & 1599 & 44.15 & 36.25 & 8.13 & 6.82 & 2.11 & 1.12 & 1.09 & 58.74 & 66.75 & 19012 & 11.91 & 3.81 \\
\hline HU & 628 & 40.31 & 34.42 & 8.64 & 6.75 & 2.24 & 1.11 & 1.21 & 59.00 & 63.49 & 12133 & 12.72 & 2.74 \\
\hline IE & 1542 & 44.48 & 35.66 & 8.25 & 7.72 & 1.67 & 1.38 & 1.41 & 57.14 & 63.13 & 47459 & 13.65 & 3.18 \\
\hline IS & 283 & 48.24 & 35.37 & 8.63 & 8.44 & 1.33 & 1.45 & 1.25 & 70.42 & 70.67 & 54038 & 14.68 & 3.78 \\
\hline IT & 863 & 46.86 & 36.39 & 8.59 & 6.51 & 2.05 & 0.95 & 1.00 & 52.24 & 59.00 & 27785 & 12.43 & 3.95 \\
\hline $\mathrm{LU}$ & 1062 & 49.28 & 35.63 & 8.38 & 7.64 & 1.91 & 1.11 & 1.14 & 57.35 & 69.16 & 48125 & 12.58 & 4.31 \\
\hline $\mathrm{LV}$ & 700 & 38.25 & 35.14 & 9.48 & 6.57 & 1.99 & 0.86 & 1.02 & 49.98 & 55.57 & 15040 & 12.73 & 3.28 \\
\hline NL & 2837 & 45.59 & 37.43 & 7.89 & 7.78 & 1.35 & 1.23 & 1.15 & 61.26 & 77.15 & 36438 & 14.02 & 3.78 \\
\hline NO & 3060 & 52.75 & 36.19 & 8.61 & 7.88 & 1.54 & 1.16 & 1.18 & 59.33 & 68.97 & 55518 & 14.31 & 3.18 \\
\hline PL & 2517 & 49.74 & 35.01 & 9.36 & 6.85 & 2.12 & 1.28 & 1.25 & 64.82 & 68.56 & 8400 & 12.70 & 2.85 \\
\hline $\mathrm{PT}$ & 1568 & 41.99 & 35.96 & 8.27 & 6.98 & 1.66 & 1.04 & 0.96 & 62.05 & 71.70 & 18924 & 9.11 & 4.45 \\
\hline SE & 2837 & 52.29 & 35.45 & 8.57 & 7.87 & 1.50 & 1.13 & 1.19 & 56.73 & 69.51 & 33903 & 13.54 & 2.78 \\
\hline SI & 1764 & 47.25 & 35.46 & 8.97 & 7.39 & 1.81 & 1.10 & 1.05 & 60.99 & 65.23 & 16611 & 12.60 & 3.33 \\
\hline SK & 1011 & 49.68 & 35.04 & 8.93 & 6.61 & 2.08 & 1.29 & 1.25 & 63.64 & 69.34 & 9456 & 12.57 & 2.87 \\
\hline UK & 2756 & 47.37 & 36.25 & 8.13 & 7.35 & 1.83 & 1.12 & 1.12 & 58.78 & 67.79 & 45801 & 13.80 & 3.36 \\
\hline
\end{tabular}

Source: own computations based on European Social Survey. Respondents younger than 20 and older than 50 are not included in the analysis. In order to obtain accurate estimates, data has been weighted using rounds' design effects. 
When establishing the links between happiness and childbearing, we want to consider many relevant intervening variables. In order to outline a general picture of our considered sample, we provide basic descriptive statistics by country for the variables considered in the subsequent analysis. For those countries present only in one of the three rounds (Bulgaria, Hungary, Island, Latvia), countries estimates are computed using design weights, namely the normed inverse of the inclusion probability. For multiple rounds countries the story is slightly more complicated since we have to account for both unequal inclusion probabilities and specific rounds design effects. The construction of the combined estimator as a weighted average of the single-rounds estimator takes into account two basic principles: firstly, an estimator from a wave with lots of respondents is trusted more than one from a wave with few respondents. Second, at a given sample size, more trust is put into the estimator that has a lower design effect (Ganninger, 2007). ${ }^{2}$

The analyzed sample appears to be gender balanced since nearly $50 \%$ of the population is male. Overall, there are more women (23662) than men (21856). Latvia, Bulgaria and Hungary are the only countries where the male population is lower or equal to $40 \%$ of the entire sample.

After having excluded respondents younger than 20 and older than 50, the mean age of the considered sample is 35 . Bulgaria is the country which has on average the youngest population (34.42), while Hungary the oldest one (37.68).

The mean level of happiness in the considered set of countries is 7.46. Countries' means range between 5.53 (Bulgaria) to 8.44 (Island). Although there is a substantial amount of between-country heterogeneity in well-being levels, there is no significant

\footnotetext{
${ }^{2}$ Design weights are not available for Latvia yet, hence we have assigned an inclusion probability equal to 1 for every respondent. Moreover, the ESS sampling expert design did not sign off the Italian sample design. We nevertheless decided to include Italy into the analysis.
} 
variation as far as gender is concerned i.e. women are not systematically happier than men or vice versa. The relevant point to consider is whether men and women have different perceptions of their situation, resulting in different levels of well-being even when their objective situation might be similar. Our results are in line with those of the existing literature where gender differences in life satisfaction are usually found to be very small. However, the literature does suggest that there is a higher variance in women's experience of depression and emotional wellbeing. That is, compared to men, women are reported to have a higher frequency of feeling depressed and experiencing negative emotions, but also have a higher frequency of experiencing positive emotions. Consequently, from a cross-sectional point of view, there might not be much difference between men and women (Van Praag B., Ferrer-I-Carbonell, 2004). It would nevertheless be interesting through longitudinal data to study temporal changes in happiness associated with childbearing and understand whether these patterns translate into gender differences in happiness.

Childbearing experiences may be measured differently. As a matter of fact, the association between happiness and childbearing may differ depending on whether one considers the first child or the total number of children. A larger number of children may impose a significant economic cost which may affect individuals' assessment of subjective well-being. For instance, Behrman et al (2005) find that happiness increases with the first born, whereas there is no significant association with happiness from further children. In our analysis we include two variables to capture these effects. The first one is the variable "At least One Child" which takes the value 1 if the individual has at least one child, 0 otherwise. On average, $60 \%$ of the respondents have at least one child; Latvia is the country where the lowest number of people has a least one child (49\%) and Bulgaria the country where the 
highest percentage of people has experienced childbearing at least once in their lives (73\%).

The second childbearing variable refers to the number of additional children beyond the first one in order to capture the potential economic burden experienced when having a large family. In Table 1 we report descriptive statistics about the total number of children present in the household. ${ }^{3}$ The total fertility rate for the analyzed sample is equal to 1.14. The average number of children per household ranges between 1.45 (Island) to 0.86 (Latvia). ${ }^{4}$

It is of outmost importance, when studying issues related to well-being it is of outmost importance to control for the partnership status. The variable "living with a partner" takes the value one when the respondent is currently living with husband/wife/partner at home i.e. we are considering marriages, civil partnerships and cohabitations. In line with the paper by Stutzer and Frey (2004), there are two main reasons why partnership contributes to individuals' well-being. First of all partnership may provide a way to increase self esteem, by providing a way of escaping from everyday's stress. Second of all, people in partnership experience lower probabilities to suffer from loneliness. The link between partnership and childbearing, namely what is generally referred to as "family", may rise within a marriage and under the more modern concept of "cohabitation". We therefore believe that when studying this association partnership status needs to be controlled for. Being in a partnership may very well affect well-being levels associated with childbearing. For example, it may

\footnotetext{
${ }^{3}$ When we construct respondents' childbearing experiences we are only able to look at current children living in the household. However, we believe this is not a main limitation since we have excluded those respondents older than age 50 , hence we are considering a set of respondents who is very likely to still have kids living at home.

${ }^{4}$ It is important to remember that our sample is restricted to individuals aged 20-50. This restriction of course affects the levels of total fertility and number of children per household.
} 
allow to reduce the economic burden incurred when raising children, and as a consequence, raise well-being levels. Moreover, happiness and more in general wellbeing are closely related to the emotional status of the respondent: being in a partnership may reduce the emotional stress associated to raising children, while the break-up with the partner may alter the perception of childbearing and induce the parent to perceive more negative feelings, resulting in higher and lower well-being levels respectively. Not surprisingly, among parents, the vast majority of the respondents (87\%) is currently living with a partner. Interestingly, the majority of the fathers is currently living with a partner (only $4 \%$ of fathers is single at the time of the interview). On the other side, $18 \%$ of the mothers (2700 respondents) is not currently living with a partner. This gender and partnership pattern highlights generally known results, namely that a couple dissolution generally results with children being assigned to their mothers; moreover, it also emerges that having children is a strong predictor of currently being in a partnership for fathers (Behrman et al 2005). ${ }^{5}$

It is recognized that income is positively associated with happiness (Blanchflower and Oswald, 2004), especially in the lower part of the income range (Argyle, 1999). Income in the ESS is recorded as a categorical variable which reflects twelve income brackets ranging from less than $€ 1800$ to $€ 120000$ or more. Each interval corresponds to a precise range (e.g. 0-up to 1800; 1800-up to 3600 etc). Respondents are asked to place their annual household income in the respective intervals. We construct a variable by assigning to each income interval its mean (e.g. 900 for the first interval etc.). The main shortfall of this methodology is that we are not controlling for substantial heterogeneity of income levels and purchasing power

\footnotetext{
${ }^{5}$ This is also the result of the fact that we can only consider those children who are resident in the household. We therefore cannot control for the fact that respondents may have non-resident children.
} 
across countries i.e. we are not dealing with a relative income measure. The descriptive table indeed shows that there is heterogeneity in income levels across countries. Switzerland is the country with the highest level of income (59000), while Bulgaria is the poorest (3600).

As far as educational levels are concerned, we observe some cross-country variation. Portugal is the country which exhibits the lowest levels of education (9.11 years on average), while Germany the highest (14.54 years on average).

The descriptive analysis reveals that there is scope for a cross-country analysis given that we observe a substantial amount of heterogeneity in well-being levels and different fertility levels across countries.

Moreover, we test whether there exist systematic differences in the level of happiness across the 25 analyzed countries. By regressing the variable happiness on country dummies, we find statistically significant differences in well-being levels. We take Denmark as the reference country in the regression since the descriptive analysis reveals that Denmark is one of the countries which exhibits really high levels of perceived happiness. All the countries exhibit statistically different levels of happiness with respect to Denmark. Not surprisingly, with the exception of Island, they all exhibit lower levels of happiness with respect to Denmark (see Table 6 in the Appendix). 


\section{Happiness and childbearing in Europe: an analysis of ESS data}

\subsection{The statistical model}

Our analysis is manifold. First we investigate the influence of the number of children on happiness. Secondly, we consider the association between being a parent i.e. regardless of the number of children, and happiness. More precisely, we consider both the effect of having at least one child and the effect of having additional children. We then investigate whether there exist country differences as far as the association between levels of happiness and parenthood is concerned. Finally, we assess whether having a boy or a girl as a first child is differently associated with well-being and whether raising a child when being in a partnership or not matters in terms of well-being.

The estimation is implemented by using a rank ordered probit model. The rank ordered probit is clearly the most appropriate technique in this context; this technique has been already used in the literature to deal with happiness variables (Alesina, Di Tella, MacCulloch 2003).

We consider the regressions separately for men and women. Even though the descriptive analysis pointed out that there do not exist substantial gender differences in well-being levels, we nevertheless think it can be interesting to investigate whether there exist gender specific linkages between happiness and childbearing. Every model includes rounds dummies in order to control for the fact that rounds' interviews were held in different years, namely in 2002, 2004 and 2006 respectively. This way we control for time varying macro-economic factors which might affect well-being levels and childbearing decisions.

The first model (extension (1)) simply considers the association between the number of children and happiness while controlling for individuals' age. Clearly other 
variables are important for happiness and need to be controlled for. Education, for example, is positively associated with income, and may again be positively associated with happiness. Moreover, also the income variable (which corresponds to the mean of each income interval) has been included: we know that there exist a complex relationship between happiness, income and childbearing which stems from the fact that richer families may be happier, given that they enjoy higher standards of living and perhaps given that they may form families more easily without worrying too much about the financial burdens implied by parenthood. Clearly it would have been appropriate to control for the health status of the respondent since healthy individuals tend to be better off in many domains, including income levels and social status. However, we are not able to control for the health status since the ESS only provides a measure of subjective level of health, which we believe to be somehow embedded into the dependent variable.

The first model consists of two separate extensions where the second one includes country dummies (with Denmark as the reference country).

The second model (extension (3)) aims at investigating whether parents, regardless of the number of children they have, are on average happier than childless respondents. The covariate at least one child is meant to capture this effect.

It is also plausible to think that the motivations behind having the first child are related to a physiological and social need of becoming parents together with family status, role expectation, and emotional rewards. On the other side, the motivations behind subsequent births could be strongly associated with providing companionship to the first child (Behrman et al 2005). If this were true, the second or the third child may have a lower or even negative impact on parents' happiness, highlighting a nonlinear effect of childbearing on well-being. In order to estimate this association, we 
sub select parents and we include in extension (4) a variable which indicates the number of additional children (after the first one).

The model presented in Table 3 is meant to disentangle country specific factors to assess whether there exist differences on how parenthood is associated with happiness across countries, possibly denoting more favourable conditions for childbearing in some countries than in others. We regress happiness on the explanatory variables including interaction terms. Interaction terms are obtained by clustering countries into the following groups based on welfare regimes and/or geographical location:

- Conservative: Austria, Belgium, France, Germany, Luxembourg, Switzerland

- Estern-Soviet: Bulgaria, Czech Republic, Hungary, Latvia, Romania, Poland, Slovenia, Slovakia.

- Liberal: United Kingdom, Ireland

- Mediterranean: Greece, Italy, Portugal, Spain

- Social Democratic: Denmark, Netherlands, Finland, Norway, Sweden

The interaction terms are constructed by multiplying each group dummy by the variable "at least one child". In the first and second specification we sub-select men and women respectively. The interaction terms capture the effect of having none or at least one child in a specific group of countries.

Table 4 considers jointly the association of partnership and fertility on respondent's well-being. In order to do so, we construct an interaction term between current partnership status and the childbearing variable "at least one child". Our aim is that of assessing whether the presence of children may enhance the happiness gains men and women derive from partnership (Behrman et al 2005). In extensions (2) and 
(3) of Table 5 we only consider women who are currently without a partner. More precisely, extension (2) investigates whether having at least one child and currently being without a partner is somehow negatively associated with the woman's subjective levels of happiness. Finally, extension (3) sub-selects mothers and investigates whether being a lone mother and having additional children after the first one result in lower happiness levels.

Finally, Table 6 includes the final set of interaction terms whereby we multiply the variable number of children times the working status of the respondent and the annual household income. The analysis is carried out separately for men and women in order to investigate whether there exist specific gender patterns in so far family, work and economic well-being are concerned.

\subsection{Results}

\subsubsection{Happiness and fertility for men and women aged $20-50$}

Looking at Table 2 and considering the parameter estimates from extension 1 through 4 gives useful information about the role of children on levels of happiness. Interestingly, the effect appears stronger for men than for women.

Extension (1) shows that the number of children in the household is positively associated with well-being for both men and women, though the effect is slightly stronger for the former than for the latter. In extension 2 we add country dummies thereby controlling for country differences. Interestingly, the association between childbearing and happiness does not change to a great extent even after controlling for country specific effects.

The effect of income, partnership status, working status and years of education on happiness are, not surprisingly, statistically significant and positive. The coefficients 
remain more or less constant throughout the models and extensions. The magnitude and sign of the coefficients coincide between men and women. Age is negatively and significantly associated with happiness for both men and women. Older people tend to perceive lower levels of well-being.

Extension (3) shows the effect of having at least one child on happiness for men and women respectively. The association is positive and significant for both genders and it is very much stronger with respect to the last extension, so that the result is confirmed and strengthened: well-being and childbearing are positively and significantly associated. In extension (3), not only the association results to be stronger, but also the gender difference is expanded with respect to extension (2) since the coefficient associated to men is much larger than the one for women.

In order to address whether there is any difference between the first born and any further children on levels of happiness, thereby keeping in line with Behrman et al (2005), we also consider a specification where the childbearing variable measures the number of additional children - conditional on having at least one child. Extension (4) shows the results. No significant association is detected between happiness levels and additional children for men. On the other side, women show a positive and significant coefficient suggesting that motivations like well-being seem to explain the progression to additional children after the first one. The result observed for men is in line with the one observed in Berhman et al (2005), where the authors suggest that motivations other than well-being seem to explain the progression to additional children. As was already pointed out, one possible explanation of this pattern is that a higher number of children tend to bring about a higher financial strain compared to families with only one child. However, this line of argument does not seem to hold for women. 
Table 2 Happiness and childbearing for men and women aged 20-50

\begin{tabular}{|c|c|c|c|c|c|c|c|c|}
\hline \multirow[t]{2}{*}{ Males } & \multicolumn{2}{|c|}{$\begin{array}{l}\text { (1) Number of } \\
\text { Children }\end{array}$} & \multicolumn{2}{|c|}{$\begin{array}{l}\text { (2) Number of } \\
\text { Children }^{\star}\end{array}$} & \multicolumn{2}{|c|}{$\begin{array}{l}\text { (3) At least one } \\
\text { child* }^{*}\end{array}$} & \multicolumn{2}{|c|}{$\begin{array}{l}\text { (4) Number of } \\
\text { additional children (for } \\
\text { parents only)* }\end{array}$} \\
\hline & -0.065 & 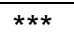 & -0.071 & $\star \star \star *$ & -0.072 & 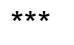 & -0.033 & * \\
\hline Age squared & 0.006 & 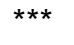 & 0.007 & *** & 0.007 & *** & 0.002 & \\
\hline Number of children & 0.028 & ** & 0.027 & ** & & & & \\
\hline Currently in partnership & 0.386 & 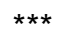 & 0.408 & 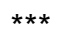 & 0.395 & $\star \star \star ~$ & 0.567 & $\star \star \star *$ \\
\hline Working & 0.237 & 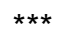 & 0.249 & 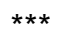 & 0.248 & $\star \star \star ~$ & 0.303 & 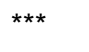 \\
\hline Annual Household Income & 0.072 & 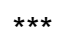 & 0.040 & $\star \star \star ~$ & 0.041 & *** & 0.043 & 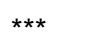 \\
\hline Years of Education & 0.013 & ** & 0.012 & $\star \star$ & 0.012 & $\star *$ & 0.006 & \\
\hline At least one child & & & & & 0.074 & *** & & \\
\hline Number of additional children & & & & & & & 0.001 & \\
\hline Round 1 (2002) & 0.053 & & 0.003 & & 0.003 & & -0.038 & \\
\hline Round 2 (2004) & 0.040 & & 0.023 & & 0.023 & & -0.002 & \\
\hline $\mathrm{N}^{\circ}$ of observations & 21856 & & 21856 & & 21856 & & 10867 & \\
\hline Females & $\begin{array}{l}\text { (1) Numbe } \\
\text { Children }\end{array}$ & & $\begin{array}{l}\text { (2) Number } \\
\text { Children* }\end{array}$ & & $\begin{array}{l}\text { (3) At least } \\
\text { child }^{\star}\end{array}$ & & $\begin{array}{r}\text { (4) Number } \\
\text { additional childr } \\
\text { parents only }\end{array}$ & $\begin{array}{l}\text { of } \\
\text { ren (for } \\
\text { y) }\end{array}$ \\
\hline Age & -0.053 & 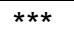 & -0.056 & 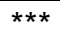 & -0.053 & 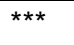 & -0.031 & ** \\
\hline Age squared & 0.005 & $* \star \star$ & 0.006 & *** & 0.005 & 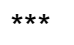 & 0.002 & \\
\hline Number of children & 0.025 & $* \star \star$ & 0.024 & ** & & & & \\
\hline Currently in partnership & 0.379 & $* \star \star$ & 0.428 & *** & 0.430 & 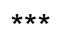 & 0.506 & $\star \star \star *$ \\
\hline Working & 0.110 & *** & 0.108 & 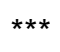 & 0.103 & 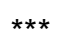 & 0.084 & ** \\
\hline Annual Household Income & 0.077 & *** & 0.040 & *** & 0.041 & *** & 0.038 & *** \\
\hline Years of Education & 0.018 & $\star \star \star *$ & 0.015 & $\star \star \star ~$ & 0.014 & $\star \star \star *$ & 0.015 & ** \\
\hline At least one child & & & & & 0.042 & * & & \\
\hline Number of additional children & & & & & & & 0.014 & ** \\
\hline Round 1 (2002) & 0.050 & ** & 0.009 & & 0.009 & & -0.007 & \\
\hline Round 2 (2004) & 0.021 & & 0.002 & & 0.002 & & -0.011 & \\
\hline $\mathrm{N}^{\circ}$ of observations & 23662 & & 23662 & & 23662 & & 15064 & \\
\hline
\end{tabular}

Source: own computations on ESS data three rounds included. * Extensions (2) (3) (4) include country dummies and Denmark is the reference country. Age squared and Annual household income have been divided by 10 and 10000 respectively. P-values: $+p<=0.10:^{*}+p<=0.05^{* \star}+p<=0.01^{\star \star \star}$. Standard errors are clustered within countries. 


\subsubsection{Parents' happiness across European countries}

Whereas our results so far have shown that there is a significant association between childbearing and happiness, we have not established if there are country differences in this relationship. This is indeed the true contribution of our paper to the current literature on happiness and childbearing since we are able to simultaneously compare the association between happiness and childbearing across Europe. The previous specification has merely controlled for country fixed effect, informing us that there are indeed differences in the level of happiness for those countries included in the analysis. In this section we re-run the regressions but with additional interaction terms as specified in the previous section. The purpose is to detect whether there exist group-specific linkages between happiness and childbearing. The regressions are performed for all respondents and then separately for men and women. The results are presented in Table 3. For simplicity we have excluded group dummies parameter estimates. The baseline is the social democratic group. The interaction terms are meant to capture whether being parent in one group of countries is more, less or equally strongly associated with well-being than in others.

When we look at extension (1) results are quite striking since no group of countries show interaction terms significantly different from the social democratic one. It does not seem that being a father in one group of country or another does make a difference in terms of well-being levels.

Extension (2) shows that women are definitely more "country sensitive" than men. As a matter of fact, mothers living in conservative, liberal, eastern-soviet countries appear to be worse-off with respect to mothers living in northern countries. A reasonable explanation is that mothers are more likely to be affected by country specific institutional factors (e.g. labour market protection, maternity leave, part-time 
employment etc.). Surprisingly, mothers living in Mediterranean countries are not substantially disadvantaged with respect to those living in northern countries i.e. the coefficient is negative but not significant.

Table 3 Being parent in different European countries

\begin{tabular}{|c|c|c|c|c|}
\hline & $\begin{array}{c}\text { Men } \\
(1)\end{array}$ & & $\begin{array}{c}\text { Women } \\
\text { (2) }\end{array}$ & \\
\hline Age & -0.069 & $* * *$ & -0.051 & *** \\
\hline Age squared & 0.007 & $\star \star \star *$ & 0.005 & $* * *$ \\
\hline At least one child & 0.081 & $\star \star *$ & 0.111 & $* * *$ \\
\hline Currently in partnership & 0.387 & $\star \star \star *$ & 0.422 & $* * *$ \\
\hline Working & 0.250 & $\star \star * *$ & 0.110 & $* * *$ \\
\hline Annual Household Income & 0.053 & $\star \star \star *$ & 0.048 & $* * *$ \\
\hline Years of Education & 0.009 & ** & 0.012 & $* * *$ \\
\hline Round 1 (2002) & 0.030 & & 0.029 & \\
\hline Round 2 (2004) & 0.046 & & 0.028 & \\
\hline At least one child*MED & -0.035 & & -0.073 & \\
\hline At least one child*CONSERVATIVE & -0.020 & & -0.068 & ** \\
\hline At least one child*LIBERAL & 0.005 & & -0.093 & $\star \star$ \\
\hline At least one child*EASTERN & -0.036 & & -0.214 & 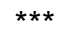 \\
\hline Number of observations & 21856 & & 23662 & \\
\hline
\end{tabular}

\subsubsection{Partnership and childbearing}

In this section we investigate over an additional interaction effect, namely that of partnership status and childbearing. Results are presented in Table 4.

Extension (1) shows that having resident biological children seems to increase couples' well-being levels, both for males and females respondents. Again, in contrast with Berhman et al (where the authors pointed out that the utility gains from partnerships do not interact with the presence of children) we observe a rather strong interaction effect between partnership-childbearing and its association to well-being levels. The coefficients are quite high, 0.201 and 0.171 for men and women respectively, and significant at the $1 \%$ level. Moreover, we notice that, when including 
the interaction terms, the effect of having at least one child on subjective happiness becomes negative for both genders. This is likely to be the result of the fact that the positive and significant association between having at least one child and happiness no longer holds once we control for the interaction term. The positive effect of having at least one child while being in a partnership fully absorbs the positive association between childbearing and well-being. This result clearly points out the fact that partnership and childbearing are strongly interconnected; this interconnection can be seen from two different and opposing points of views: having children increases the utility gains derived from partnership or raising children while being in a partnership strengthen the association between happiness and childbearing.

Finally extension (2) and (3) investigate if and to what extent women perceive the burden of having to raise children without a partner. The analysis is exclusively done for women, since a very limited number of men is currently without a partner and, at the same time, reports to have children living in the household (only 407 observations, which represent only $4 \%$ of the total number of men who is currently not living with a partner).

The association between happiness and childbearing for those women currently living without a partner is negative but not significant when considering the association between having at least one child and well-being levels. ${ }^{6}$ Single mothers with more than one dependent child at home seem to be more disadvantaged than those who have an only child living in the household. The coefficient associated to the variable "Number of additional children" is negative $(-0.083)$ and significant at the $1 \%$ level.

\footnotetext{
${ }^{6}$ Interestingly, when we don't control for working status the association between happiness and having at least one child while being without a partner is negative and significant.
} 
Whether these results capture the economic burden, the psychological distress, the negative feelings associated with the loss of a partner or a combination of the three of them cannot be easily understood through this model. Extensions (2) and (3) nevertheless suggest that the positive association between happiness and childbearing (as it emerges from the analysis of the previous sections) is reversed once we only consider women who are currently without a partner.

\section{Table 4 Childbearing \& Partnership}

\begin{tabular}{|c|c|c|c|c|c|c|}
\hline \multirow[t]{2}{*}{ Males } & \multicolumn{2}{|c|}{$\begin{array}{l}\text { (1) Partnership \& } \\
\text { Childbearing }\end{array}$} & & & & \\
\hline & -0.071 & $\star \star \star *$ & & & & \\
\hline Age squared & 0.007 & $\star \star \star *$ & & & & \\
\hline At least one child & -0.123 & * & & & & \\
\hline $\mathrm{N}^{\circ}$ of additional children & 0.008 & & & & & \\
\hline Currently in a partnership & 0.359 & $\star \star \star *$ & & & & \\
\hline Partnership Status* At least one child & 0.212 & $\star \star \star ~$ & & & & \\
\hline Working & 0.250 & $\star \star \star *$ & & & & \\
\hline Annual Household Income & 0.040 & $\star \star * *$ & & & & \\
\hline Years of education & 0.012 & $\star \star *$ & & & & \\
\hline Round 1 (2002) & 0.003 & & & & & \\
\hline Round 2 (2004) & 0.023 & & & & & \\
\hline $\mathrm{N}^{\circ}$ of observations & 21856 & & & & & \\
\hline Females & $\begin{array}{l}\text { (1) Partnershi } \\
\text { Childbearin }\end{array}$ & & (2) Lone w & omen & (3) Lone $\mathrm{mc}$ & others \\
\hline Age & -0.054 & 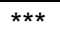 & -0.085 & 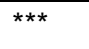 & -0.031 & \\
\hline Age squared & 0.005 & $\star \star * *$ & 0.010 & $\star \star \star *$ & 0.003 & \\
\hline At least one child & -0.104 & $\star \star \star *$ & -0.047 & & & \\
\hline $\mathrm{N}^{\circ}$ of additional children & 0.019 & & & & -0.068 & ** \\
\hline Currently in a partnership & 0.338 & 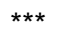 & & & & \\
\hline Partnership Status* At least one child & 0.176 & $\star \star \star *$ & & & & \\
\hline Annual Household Income & 0.039 & $\star \star \star *$ & 0.038 & 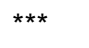 & 0.046 & 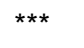 \\
\hline Working & 0.109 & $\star \star \star *$ & 0.211 & $\star \star \star *$ & 0.209 & $\star \star \star *$ \\
\hline Years of education & 0.014 & $\star \star \star *$ & 0.024 & $\star \star \star *$ & 0.026 & $\star \star \star *$ \\
\hline Round 1 (2002) & 0.008 & & -0.068 & $\star *$ & -0.130 & $* \star *$ \\
\hline Round 2 (2004) & 0.002 & & -0.034 & & -0.108 & $\star *$ \\
\hline $\mathrm{N}^{\circ}$ of observations & 23662 & & 7506 & & 2698 & \\
\hline
\end{tabular}

Source: own computations on ESS data three rounds included. "Age squared" and "Annual household income" have been divided by 10 and 10000 respectively. Extensions include country dummies and Denmark is the reference country. P-values: $+p<=0.10:^{*}+p<=0.05^{* *}+p<=0.01^{* \star *}$. Standard errors are clustered within countries. 


\subsubsection{Working, income levels and childbearing}

Given the substantial differences observed across genders throughout the previous analyses, in this final set of regression we investigate over two important issues which are generally considered as controversial across men and women. Table 6 shows the results.

Extension (1) investigates over the relationship between job status and the number of children. The interaction term is obtained multiplying the variable "working" (binary variables taking the value 1 if the respondent is currently employed) and the number of children the respondent declares to have at the time of the interview.

Extension (2) is meant to study whether there exist any correlation between wellbeing levels and household income levels interacted with the number of children. Clearly, the main focus lies in understanding how job status, income levels and family size are differently associated with men and women declared well-being levels.

Extension (1) shows that those fathers who are currently working appear to be better off once the family gets larger. On the contrary, it seems that reconciling work and a large family result in lower well-being levels for women since the interaction term displays a negative and significant coefficient.

Finally, extension (2) shows that the interaction between annual household income and the number of children is not significantly associated with men's well-being levels. Conversely, the interaction term displays a positive and significant association as far as women are concerned. Having a larger family while enjoying higher income levels is positively associated with well-being levels. There may be several good explanation for this final set of results. For instance, higher income levels may mean higher purchasing powers in so far childcare services are concerned. 
Table 5 Work, income and family size

\begin{tabular}{|c|c|c|c|c|}
\hline \multirow{2}{*}{$\begin{array}{ll} & \text { Males } \\
\text { Age }\end{array}$} & \multicolumn{2}{|c|}{$\begin{array}{l}\text { (1) Working status \& } \\
\text { Childbearing }\end{array}$} & \multicolumn{2}{|c|}{ (2) Income \& Childbearing } \\
\hline & -0.069 & $\star \star *$ & -0.071 & $* \star *$ \\
\hline Age squared & 0.007 & $* * *$ & 0.007 & $* \star *$ \\
\hline $\mathrm{N}^{\circ}$ of children & -0.012 & & 0.023 & $\star \star$ \\
\hline Currently in a partnership & 0.411 & $* \star *$ & 0.409 & $\star * *$ \\
\hline Working & 0.221 & $* * *$ & 0.250 & $\star \star \star *$ \\
\hline Working * $\mathrm{N}^{\circ}$ of children & 0.044 & $\star *$ & & \\
\hline Years of education & 0.012 & ** & 0.012 & $\star \star$ \\
\hline Annual Household Income & 0.040 & $* \star *$ & 0.039 & 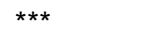 \\
\hline Annual Household Income ${ }^{*} N^{\circ}$ of children & & & 0.001 & \\
\hline Round 1 (2002) & 0.004 & & 0.004 & \\
\hline Round 2 (2004) & 0.023 & & 0.023 & \\
\hline $\mathrm{N}^{\circ}$ of observations & 21856 & & 21856 & \\
\hline
\end{tabular}

$\mathrm{N}^{\circ}$ of observations

(1) Working status \&

Females

\begin{tabular}{|c|c|c|c|c|}
\hline Age & -0.057 & $\star \star \star *$ & -0.055 & 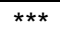 \\
\hline Age squared & 0.006 & $\star \star \star *$ & 0.005 & $\star \star \star ~$ \\
\hline $\mathrm{N}^{\circ}$ of children & 0.034 & $\star \star \star *$ & 0.004 & \\
\hline Currently in a partnership & 0.428 & $* \star \star$ & 0.431 & 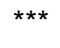 \\
\hline Working & 0.128 & $\star \star \star *$ & 0.108 & 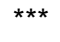 \\
\hline Working ${ }^{*} \mathrm{~N}^{\circ}$ of children & -0.017 & * & & \\
\hline Years of education & 0.015 & $* \star *$ & 0.014 & ** \\
\hline Annual Household Income & 0.040 & $* \star *$ & 0.033 & 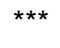 \\
\hline Annual Household Income ${ }^{*} \mathrm{~N}^{\circ}$ of children & & & 0.006 & ** \\
\hline Round 1 (2002) & 0.009 & & 0.010 & \\
\hline Round 2 (2004) & 0.002 & & 0.003 & \\
\hline $\mathrm{N}^{\circ}$ of observations & 23662 & & 23662 & \\
\hline
\end{tabular}

Source: own computations on ESS data three rounds included. "Age squared" and "Annual household income" have been divided by 10 and 10000 respectively. Extensions include country dummies and Denmark is the reference country. P-values: $+p<=0.10:{ }^{*}+p<=0.05: *$ Standard errors are clustered within countries. 


\section{Discussion}

Do children make us happy? In light in recent changes in fertility patterns and the rising importance attributed to well-being levels, it becomes interesting to study whether there exists any significant association between them. In this article we argue that there is a positive and significant association between subjective levels of happiness and parenting; we are, however, not able to establish any causal link due to the cross-sectional nature of our data. Evidently, our results appear to be in line with those of Behrman et al (2005). As a matter of fact, it seems that parents are happier than non parents, given that, even after controlling for individual and country characteristics, coefficients generally stay positive and significant. When we regress happiness on the number of children, the association between childbearing and happiness is rather small and it is larger for fathers than for mothers. When we instead search for the overall association between being a parent or not in terms of happiness, the effect is much more clear and determinate: parents are definitely happier than non parents on average. At the same time, we find that additional children, after the first born, do not increase fathers' subjective well-being while they increase mother's subjective well-being. One may as a result conclude that children make us happier, at least up to a certain extent.

Parenthood seems to have peculiar characteristics in different European countries: the degree of happiness of mothers changes if we look at specific European regions. More precisely, the very interesting and striking result is that fathers are not systematically happier or unhappier in one region than another, while it is the case that being mothers in countries other than Social Democratic does results in lower well-being levels, with the exception of Mediterranean ones. It is far from easy to fully motivate these patterns since these groups of countries which exhibit significant 
coefficients are a combination of poorer countries (Eastern European), countries with low welfare provision (Liberal) and countries with weak family ties. The reasons behind the fact that being mothers in these countries result in more disadvantaged conditions is probably the result of a combination of factors such as the general economic conditions of a country, welfare provision, institutional setting (e.g. childcare services, labour market flexibility, maternity leave etc) and cultural and social norms (e.g. provision of informal childcare services through family links and intergenerational transfers).

We find a very strong interconnection between happiness, partnership and childbearing. By including the interaction term (at least one child and partnership status) we are able to estimate a separate association between happiness and childbearing for those who are currently in a partnership and those who are not living with a partner. Being simultaneously in a partnership and having children clearly results in higher well-being levels; conversely having children while being single corresponds to a more disadvantaged condition. Whether this is the result of the fact that having children increases the happiness gain a couple derives from partnership or its mirror image, namely that raising children without a partner lowers the wellbeing derived from childbearing, cannot be clarified with the type of data we are dealing with. Furthermore, the positive and significant association between childbearing and happiness no longer holds once we only consider women who are currently not living with a partner.

Finally, it seems that working status and household income levels interacted with childbearing and are strongly associated with mother's well-being levels. Having a large family while working is associated with lower well-being levels for mothers, while the opposite is true for men. This result possibly highlights a difficult role for 
working mothers. Conversely, enjoying higher standard of living and having a large family is generally correlated with higher happiness for mothers. This final set of results ultimately highlights the existence of a gender dimension in the association between happiness and childbearing.

Summing up, based on our results, the association between happiness and childbearing appears to be positive and significant. It is, especially for women, strictly related to the partnership status, job status and income levels. As a matter of fact, the happiness gains associated to childbearing disappear once the partner is no longer present and having an increasing number of children while working is negatively associated with mothers' well-being levels.

It is however possible to generalize our results only to a limited extent due to the basic cross-sectional nature of our analysis and the evident selectivity issues we are not able to deal with. As was clearly stated in the introduction, our main contribution to the literature on happiness and childbearing is the comparative perspective of our work. Taking such a wide comparative perspective (our analysis is done for 25 European countries), to the best of our knowledge, has never been done before.

Given the peculiarity of the topic and the fact that it has not been studied much in the literature so far, there are of course many challenges for future research.

First of all it would be interesting to study whether the association between childbearing and well-being varies when one confronts parents whose children are still living at home with those whose kids have already exited it. More precisely, this type of analysis would investigate whether the association between childbearing and well-being changes when children are no longer economically dependent on parents after they leave the parental household. 
Finally, it would be interesting to include into the model a larger set of interaction effects hereby accounting for not only where parents are currently living (as we did now by interacting country dummies with the variable "at least one child") but also for other factors. These interaction effects could capture both macro factors (e.g. GDP levels of a country) and respondents' characteristics (e.g. level of education, whether you receive help from grandparents etc.). 


\section{References}

Aassve A., lacovou M., Mencarini L. (July 2006), Youth Poverty and Transition to Adulthood in Europe, Demographic Research 15(2): 21-50

Alesina A., Di Tella R., MacCulloch R. (July 2003), Inequality and Happiness: are Europeans and Americans different?, Journal of Public Economics, volume 88, issues 9-10: pp 2009-2042

Argyle M. (1999), Causes and Correlates of Happiness, in (D. Kahneman, E. Diener, and N. Schwarz eds.), Well-being: The Foundations of Hedonic Psychology, New York: Russell Sage Foundation, pp.353-73

Aslam A., Corrado L. (2007), No man is an Island : the Inter-personal Determinants of Regional Well-Being in Europe, Cambridge Working Papers in Economics.

Barro R., Becker G. (1988), A Reformulation of the Economic Theory of Fertility, The Quarterly Journal of Economics, volume 103, no. 1 (February 1988): pp. 1-25

Becker G. (1991), A Treatise on the Family, Cambridge, Massachusetts, Harvard University Press, 1991. xii, 424 p.

Behrman J., Kohler H., Skytthe A. (September 2005), Partnership + Children = Happiness? The Effects of Partnerships and Fertility on Well-Being, Population and Development Review, volume 31, issue 3: pp. 407-445

Billari F. (2008), The happiness commonality: Fertility decisions in low-fertility settings, GGP Conference May 2008, Geneva (http://www.unece.org/pau/ggp/conf/contrib.htm)

Blanchflower D., Oswald A. (2004), Well-being over time in Britain and the USA, Journal of Public Economics, volume 88(2004): pp. 1359-1386

Boldrin M., Jones L. (2002), Mortality, Fertility and Saving in a Malthusian Economy, Review of Economic Dynamics, volume 5, issue 4: pp. 775-814

Caldwell J. (1978), A Theory of Fertility: From High Plateau to Destabilization, Population and Development Review, volume 4: pp. 553-577

Clark A., Frijters P., Shields M. (September 2006), Income and Happiness: Evidence, explanations and economic implications, Working Paper N.5, PSE, Paris

Diener E. (1984), Subjective well-being, Psychological Bulletin, volume 95(3): pp. 542-75

Easterlin R. (1994), Will raising the incomes of all increase the happiness of all?, Journal of Economic Behaviour and Organization, volume 27 (1995): pp. 35-47

Easterlin R. (2001), Income and Happiness: Towards a unified Theory, Economic Journal, volume 111(473): pp. 456-484

Easterlin R. (2003), Explaining Happiness, Proceedings of the National Academy of Sciences of the United States of America, volume 100(19): pp. 11176-11183

Easterlin R. (2005), Is there an "iron law for happiness"?, IEPR Working Paper N.05.8, Department of Economics, University of Southern California

Easterlin R., Zimmermann A. (2006), Happily ever after? Cohabitation, Marriage, Divorce and happiness in Germany, Population and Development Review, volume 32, issue 3: pp. 511-528

Esping-Andersen, G. (1999), Social Foundations of Post industrial Economies. Oxford: Oxford University Press 1999: pp. 24-27

Ferrera M. (1996), The "Southern Model" of welfare in social Europe, Journal of European Social Policy, volume 6, N.1: pp. 17-37

Frey B.,Stutzer A. (2004), Does marriage make people happy, or do happy people get married?, The Journal of Socio-Economics, volume 35: pp. 326-347 
Leibenstein H. (1975), The Economic Theory of Fertility Decline, The Quarterly Journal of Economics, volume 89, N.1 (Feb., 1975): pp. 1-31

Moav O. (2005), Cheap Children and the Persistence of Poverty, The Economic Journal, volume 115(500): pp. 88-110

Neher P. (1971), Peasants, Procreation and Pensions, The American Economic Review, volume 61, issue 3: pp.380-389.

Oswald A. (April 1997), Happiness and Economic Performance, Economic Journal, volume 107: pp.1815-1831

Reher, D. (1997), Perspectives on the family in Spain, Past and Present, Oxford, England, Clarendon Press, 1997. xv, 356 p.

Scrimshaw, S.C.M. (September 1978), Infant Mortality and Behaviour in the Regulation of Family Size, Population and Development Review, volume 4, N.3: pp. 383-403

Van Praag B., Ferrer-I-Carbonell (2004), Happiness Quantified: A Satisfaction Calculus Approach, Oxford University Press

Veenhoven R. (1993), Happiness in Nations, Subjective Appreciation of Life in 56 Nations 1946-1992, Rotterdam: Erasmus University

Veenhoven R. (2000), Freedom and Happiness, a comparative study in 46 nations in the early 1990's, in Diener, E. \& Suh, E.M. (eds) "Culture and subjective wellbeing”, MIT press, Cambridge, MA USA, 2000, pp. 257-288 


\section{Appendix}

AT Austria

BE Belgium

BG Bulgaria

$\mathrm{CH}$ Switzerland

CZ Czech Republic

DE Germany

DK Denmark

ES Spain

FI Finland

FR France

GR Greece

HU Hungary

IE Ireland

IS Island

IT Italy

LU Luxembourg

LV Latvia

NL Netherlands

NO Norway

$\mathrm{PL} \quad$ Poland

PT Portugal

SE Sweden

SI Slovenia

SK Slovakia

UK United Kingdom 
Table 6 Differences in the level of happiness across Europe

\begin{tabular}{|c|c|c|c|}
\hline Country & $b$ & & St. Err. \\
\hline Round 1 (2002) & -0.01 & & 0.01 \\
\hline Round 2 (2004) & -0.01 & & 0.01 \\
\hline IS & 0.13 & * & 0.07 \\
\hline $\mathrm{FI}$ & -0.15 & $\star \star \star *$ & 0.03 \\
\hline $\mathrm{CH}$ & -0.16 & *** & 0.03 \\
\hline NO & -0.27 & $\star \star \star *$ & 0.03 \\
\hline SE & -0.28 & $\star * \star$ & 0.03 \\
\hline IE & -0.37 & $\star \star \star *$ & 0.04 \\
\hline LU & -0.37 & $* \star *$ & 0.04 \\
\hline $\mathrm{BE}$ & -0.40 & $\star \star \star *$ & 0.03 \\
\hline NL & -0.41 & $* \star *$ & 0.03 \\
\hline AT & -0.44 & *** & 0.03 \\
\hline ES & -0.46 & *** & 0.03 \\
\hline SI & -0.55 & *** & 0.03 \\
\hline FR & -0.60 & 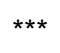 & 0.03 \\
\hline UK & -0.63 & 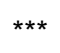 & 0.03 \\
\hline $\mathrm{DE}$ & -0.74 & 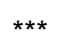 & 0.03 \\
\hline$C Z$ & -0.75 & 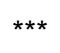 & 0.04 \\
\hline PT & -0.82 & $\star \star \star *$ & 0.03 \\
\hline PL & -0.87 & $\star \star \star *$ & 0.03 \\
\hline GR & -0.87 & $\star \star \star *$ & 0.03 \\
\hline $\mathrm{HU}$ & -0.93 & $\star \star \star *$ & 0.05 \\
\hline SK & -0.98 & $\star \star \star ~$ & 0.04 \\
\hline LV & -1.03 & 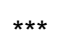 & 0.05 \\
\hline IT & -1.06 & 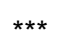 & 0.04 \\
\hline BG & -1.45 & 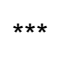 & 0.05 \\
\hline $\mathrm{N}^{\circ}$ Obs. & \multicolumn{2}{|c|}{45518} & \\
\hline
\end{tabular}

Source: own computation based on ESS data. Note: standard errors in parenthesis. P-values: $+p<=0.10:^{*}+p<=0.05^{* *}+p<=0.01^{* \star *}$. Denmark is the reference country 